UCRL- 91936

PREPRINT

CONF-850504-.33

\title{
TECHNOLOGY OF MAGNETICALLY DRIVEN ACCELERATORS
}

\author{
D. L. Birx \\ S. A. Hawkins \\ S. E. Poor \\ L. L. Reginato \\ D. Rogers, Jr. \\ M. W. Jmith \\ This paper was prepared for subrittal to \\ 1985 Particle Accelerator Conference \\ Vancouver, B.C., Canada \\ llay 13-16, 1985
}

March 26, 1935

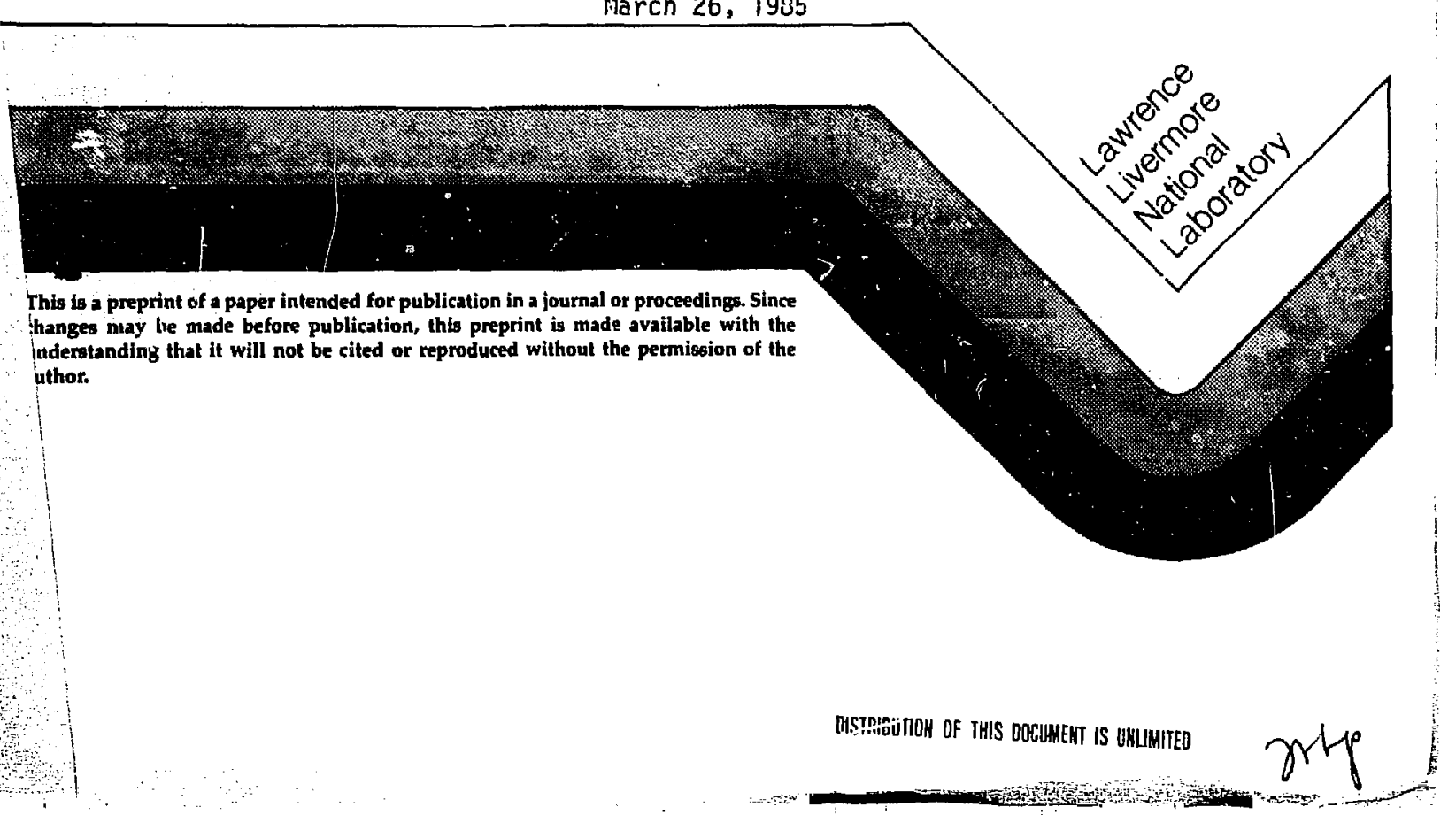


TECHNOLOGY OF MAGNETICALLY ORIVEN ACCELERATORS*

D. L. Birx, S. A. Hawkins, S. E. Poor, L. L. Reginato, M. W. Smith

Lawrence Livermore National Laboratory

University of California

Livermore, CA 94550

March 26, 1985

UCRL--91936

DE85 011857

\begin{abstract}
$\underline{\text { ABSTRACT }}$
DE85 011857

The marriage of Induction Linac technology with Nonlinear Magnetic Modulators has produced some unique capabilities. It appears possible to produce electron beams with average currents measured in amperes, at gradients exceeding $1 \mathrm{MeV} / \mathrm{meter}$, and with power ifficiencies approaching 50\%. A $2 \mathrm{MeV}$, $5 \mathrm{kA}$ electron accelerator has been constructed at the Lawrence Livermore National Laboratory (LLNL) to demonstrate these concepts and to provide a test facility for high brightness sources. The pulse drive for the accelerator is based on state-of-the-art magnetic pulse compressors with very high peak power capability, repetition rates exceeding a kilohertz and excellent reliability.
\end{abstract}

*Work parformed jointly under the auspices of the U. S. Department of Energy by Lawrence Liyermore National Laboratory under contract W-7405-ENG-48 and for the Department of Defense under Defense Advanced Research Projects Agency ARPA Order No. 4395 Amendment No. 31, monitored by Naval Surface Weapons Center under document number N60921-85-P0W0001; and SDI0/BMD-ATC MIPR No. W3-RPD-53-A127. 


\section{INTRODUCTION}

We are anticipating future needs beyond the capabilities of the spark-gap switches we developed for the Advanced Test Accelerator (ATA). We are continuing our efforts on magnetic pulse compressors that use nonlinear magnetic components and have designed reliable, high-current pulse compressors capable of generating continuous, $50 \mathrm{~ns}, 250 \mathrm{kV}$ pulses at repetition rates exceeding $1 \mathrm{kHz}$.

The Laboratory's Advanced Test Accelerator (ATA), funded by the Defense Advanced Research Projects Agency, is a $50 \mathrm{MeV}, 10 \mathrm{kA}$ inducticn linear accelerator with a pulse length lasting up to 50 ns. Operation is normally at one Hertz average, however, the accelerator pulse power has the capability of burst mode operation at one kilohertz. This ten-pulse burst can be repeated every two seconds, giving the machine an average repetition rate of five pulses per second.

This performance, which makes the ATA unique among pulse power machines, came as the result of research on a novel, coaxial, gas-blown spark gap. The ATA contains modular, $250 \mathrm{kV}$ induction- accelerator cells, each driven by a single pulse power unit. Each unit consists of a resonant transformer (1:10 step-up), a water-filled Blumlein pulse-forming line (PFL) for energy storage, and the aforementioned spark gap to discharge the PFL into the accelerator cell.

The initial commutation in the chain is performed by six fast recovery, glass-envelope thyratrons, four operating in the forward and two in the reverse direction. These tubular thyratrons, specially made for high-peakpower, low-duty-factor applications, transfer energy held in intermediate 
storage through the $1: 10$ transformer and into the PFL. The transfer is completed in $20 \mu \mathrm{s}$, and the tubes recover their ability to hold voltage in another $20 \mu \mathrm{s}$.

A hiatus of 1 ms or more between pulses is necessary so the discharge products $c$ an be blown out of the spark gap. In theory, higher repetition rates could have been achieved by increasing the velocity of the gas that blows them out. Any significant increase is impractical, however, since the power required from the blower scales as the cube of the repetition rate, and it is already at $11.2 \mathrm{~kW}$ per gap for $1 \mathrm{kHz}$ operation.

Figure 1 , which schematically compares the pulse power requirements for the ATA and the Stanford Linear Accelerator (SLAC), suggests part of the reason why we needed to use spark gaps in the ATA. Although the pulse energy supplied to a SLAC radio-frequency accelerator section is essentially the same as that supplied to an ATA induction cell, the power level to the ATA is about a hundred times larger because the pulse is so much shorter.

The energy compression supplied by the spark gap (switch $S_{2}$ in Fig. lb) supplied this power gain. The combination of a $250 \mathrm{kV}$ operating voltage and a requirement for a current rise of $10 \mathrm{kA} / \mathrm{ns}$ (or $10^{13} \mathrm{~A} / \mathrm{s}$ ) forced us to use the crude but effective high-pressure spark-gap technology. However, such technology is not adequate to achieve high repetition rates for future applications.

Research into alternative switching schemes began almost before the first spark gaps went into use. 


\section{MAGNETIC PULSE COMPRESSION}

The basic circuit for magnetic pulse compression is essentially the same as originally conceived in the 1950s. The fundamental principle involved is to use the large changes in permeability exhibited by saturating ferri-(ferro-) magnetic materisis to produce large changes in impedance. Figure 2 a shows the permeability changes in a representative saturable magnetic: material, and Fig. 2b illustrates the standard technique for capitalizing on this behavior. First, a repetitive power source (using existing technology) generates the initial pulse. As this pulse propagates through the network, it goes through several states of compression until it achieves the desired output shape.

By using multiple stages as shown, it is possible to achieve a much larger effective change in impedance than can be obtained from a single stage. In fact, the effective change in impedance is limited only by the physical layout and materials properties. Figure $2 \mathrm{c}$ illustrates the results of the compression process.

The operation of this circuit can be described as follows. Capacitor $C_{1}$ charges through inductance $L_{0}$ until inductance $L_{1}$ saturates, becoming much less than $L_{0}$. Once this happens, $C_{2}$ will begin to charge from $C_{1}$ through

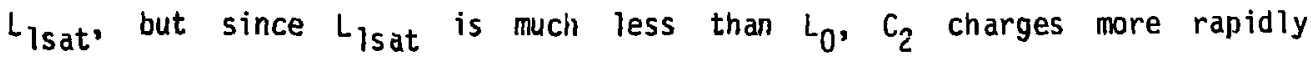
than $C_{1}$ did. This process continues through the successive stages until $C_{n}$ discharges into the load through $L_{n}$ sat ${ }^{*}$

To make this process efficient, we design each of these successive stages so that saturation occurs at the peak of the voltage waveform. Segment 1 to 2 
in the hysteresis loop of $\mathrm{Fig} .2 \mathrm{a}$ is the active or high-permeability region during which the inductor impedes current flow; the leveling off of the curve at point $z$, reached at the peak of the voltage waveform, indicates core saturation when the inductor achieves a low impedance. During segment 2 to 4 , the core is reset to its original state, ready for the next cycle.

Aside from creating the ability to operate at increased repetition rates, the installation of magnetic pulse compressors appeared warranted on the basis of reliability and low maintenance. The benefits to the experimental program were also considerable.

\section{THE ATA UPGRADE PROTOTYPE}

Since October 1980, when we first began to work with magnetic switches, we have completed installation and final testing of a prototype magnetic switch package to replace the spark gaps in the ATA power units. The challenge was not to prove that a magnetic switch would do the job but rather to produce a unit that would fit the existing space, use as much of the existing equipment as possible, and be as inexpensive and reliable as possible.

The problem was further complicated by a desire for a peak repetition rate exceeding several kilohertz and an average repetition rate of a least $100 \mathrm{~Hz}$. We also wanted the ability to operate at $1 \mathrm{kHz}$ for up to one minute in every ten. 
Figure 3 compares the two systems for driving ATA cells, the original one (containing a resonant transformer, a gas-blown spark gap, and a Blumlein line) and the new pulse compressor based on nonlinear magnetic elements. The latter is relatively inexpensive, and its performance surpasses that of any other system. Table I partially documents the capabilities demonstrated by this protot.ype.

Figure 4 compares the physical dimensions of the two systems. The existing pulse power unit is somewhat shorter than the new magnetic replacement, but it drives only one cell instead of two. The new unit. consists of an input step-up transformer, one stage of compression to charge the transmission line, a second stage of compression, and the output coupling transformer. The output transformer $c$ an be housed as part of the magnetic pulse generator or as part of the load for best impedance matching.

Adding coupling transformers at both the input and the output of the magnetic pulse compressor improves the system's versatility by permitting it to achieve the desired output pulse while allowing the compression stages and the input switching device to operate at their most efficient values of voltage and current.

At this point in the evolution of the pulse-shaping hardware, we can design the transformer turns and the interstage capaciturs as integral parts of the system. The resulting magnetic compressor is simple and extremely reliable, and it satisfies all the required performance specifications.

A desire to double the individual accelerator-cell voltage, coupled with the difficulty of sending $500 \mathrm{kV}$ pulses around the system, prompted us to 
adopt an alternate procedure. We send the output from the magnetic driver (about $170 \mathrm{kV}$ peak) down to the accelerator cells via two $4 \Omega$, semi-rigid, water-filled transmission lines. There, a pulse transformer provides a 3:1 voltage step-up and a ferrite pulse sharpener steepens the rise time. Figure 5 shows the physical layout and the two voltage waveforms.

A cross-sectional view of the accelerator cell connection is provided by Fig. 6. Here the ferrite shock line sharpeners and the $\mathrm{CuSO}_{4}$ compensation loads can also be seen.

\section{THE HIGH BRIGHTNESS TEST STAND (HBTS)}

The desire to construct a test stand for electron gun design provided an excellent opportunity to deploy this technology. Whiie magnetic modulators had been deployed experimentally in isolated parts of both the Experimental Test Accelerator (ETA) and the Advanced Test Accelerator (ATA), this was the first case where they were solely responsible for the accelerator drive. A simplified schematic of the HBTS is provided by Fig. 7.

The two MAG I's each supply the $500 \mathrm{kV}$ accelerating potential to two of the four accelerator cells. While the total accelerator potential has been run as high as $2 \mathrm{MeV}$, most of the experimental work to date has been performed between 1 and $1.5 \mathrm{MeV}$.

The primary goals of the HBTS are to generate a $1-2 \mathrm{kA}$ electron beam of the highest brightness $\left(>10^{5} \mathrm{Amps} / \mathrm{cm}^{2}\right.$-steradian) possible and at considerable average power. Upon meeting these requirements the HBTS will probably serve as the electron source for the ATA Free Electron Laser 
experiments. A cross sectional view of the accelerator design showing the preliminary electron optics as well as the collimator diagnostic package; and some of the initial results provided are shown in Fig. 8 . The electron beam quality masured at this time corresponded to a brightness of $2 \cdot 10^{5}$ Amps $/ \mathrm{cm}^{2}$ steradian.

The accelerator as shown in Fig. 8 is configured as a pentode electron gun employing a graphite field emission cathode.

While the experiments with this configuration were initially quite successful, none of various field emission cathodes tried were capable of meeting the high average power requirements. During operation above $50 \mathrm{~Hz} \mathrm{cw}$ the cathodes soon showed signs of non-uniform emission and after several minutes ceased to emit at all. Upon returning to lower repetition rates the cathodes would recover to their original performance.

It is the belief of the authors that the operation of field emission cathodes is strongly dependent on the presance of condensed $g a s$ at the surface. Application of a high electric field stress is accompanied by the evaporation and subsequent ionization of this material thereby creating a plasma from whose sheath electrons can be extracted. Operation at righ duty factors appears to deplete this gas supply.

Experiments are currently in progress which employ thermal cathode designs. It is hoped that the use of a dispenser cathode will allow us to meet both the brightness and average beam power requirement. 


\section{SUMMARY}

In summary it seems that the marriage of Induction Accelerators with Magnetic Compression Technology has provided some unique capabilities.

As a final nite it may be worth mentioning that while most of the accelerator operating time has been dedicated to research topics related to national defense, some initial experiments on radiation food processing have already been carried out in conjunction with the University of California at Davis, directed at documenting similarities and differences between this technique of radiation processing and the more conventional method of exposure to radioactive isotopes. 
Table I

Comparison of output pulse parameters of the current spark-gap driver of the Advanced Test Accelerator and the MAG-1 prototype of an upgraded magnetic comrression system.

Parameter

Peak output power, GW

Pulse rise time (10-90\%) per cel1, ns

Pulse length (FWHM), ns

Pulse energy, J

Efficiency (including resonant transformer), $\%$ - 70

Voltage (2-cell driver) at $18 \mathrm{kA} / \mathrm{cell}, \mathrm{kV}$

Voltage (1-cell driver) at $25 \mathrm{kA} / \mathrm{ce} 11, \mathrm{kV}$

Pulse-to-pulse jitter at up to $\mathrm{i} \mathrm{kHz}$, ns

Peak burst rate ( 5 pulses), $\mathrm{kHz}$

Peak average repetition rate at $10 \%$ duty factor, $\mathrm{kHz}$
Spark

Gap

2.5

18

70

350

100

200

$\pm 1$

1

0.1
Magnetic Compression

10

15

80

800

.80

300

450

$\pm 0.5$

$>10$

1 
Fig. 1 Power conditioning comparison for RF linac and induction accelerator. Fig. 2 Diagrams outlining the operation of magnetic pulse compression. (a) The hysteresis (B-H) ionp of a typical saturable magnetic material. (b) Simplified schematic of a magnetic pulse compressor. The elements marked $L_{1}, L_{2}$, and $L_{n}$ are nonlinear indictors. (c) Typical voltage waveforms associated with a magnetic pulss compressor.

Fig. 3 Simplified schematics of pulse power chains for the ATA induction linear accelerator. (a) The present system, which uses a spark gap and Blumlein pulse formers. (b) The non-linear magnetic drive proposed for an upgrade of the ATA.

Fig. 4 Geometric comparison between (a) the existing pulse power unit and (b) the prototype of the recently developed upgrade. The magnetic pulse compressor is longer and has about the same diameter as the existing pulse power unit, but it feeds two accelerator cells instead of one, making it possible to use only half as many units.

Fig. 5 Initial tests of the MAG-1 (ATA upgrade prototype) driving a typical ATA cell. The diagram indicates the points in the circuit at which the voltages were measured.

Fig. 6 HV transition to accelerator cell.

Fig. 7 Initial configuration high brightness test stand (HBTS).

Fig. 8 cross-sectional view of the HBTS accelerator module; HBTS accelerator output waveforms, all pulses $20 \mathrm{~ns} / \mathrm{div}$. 

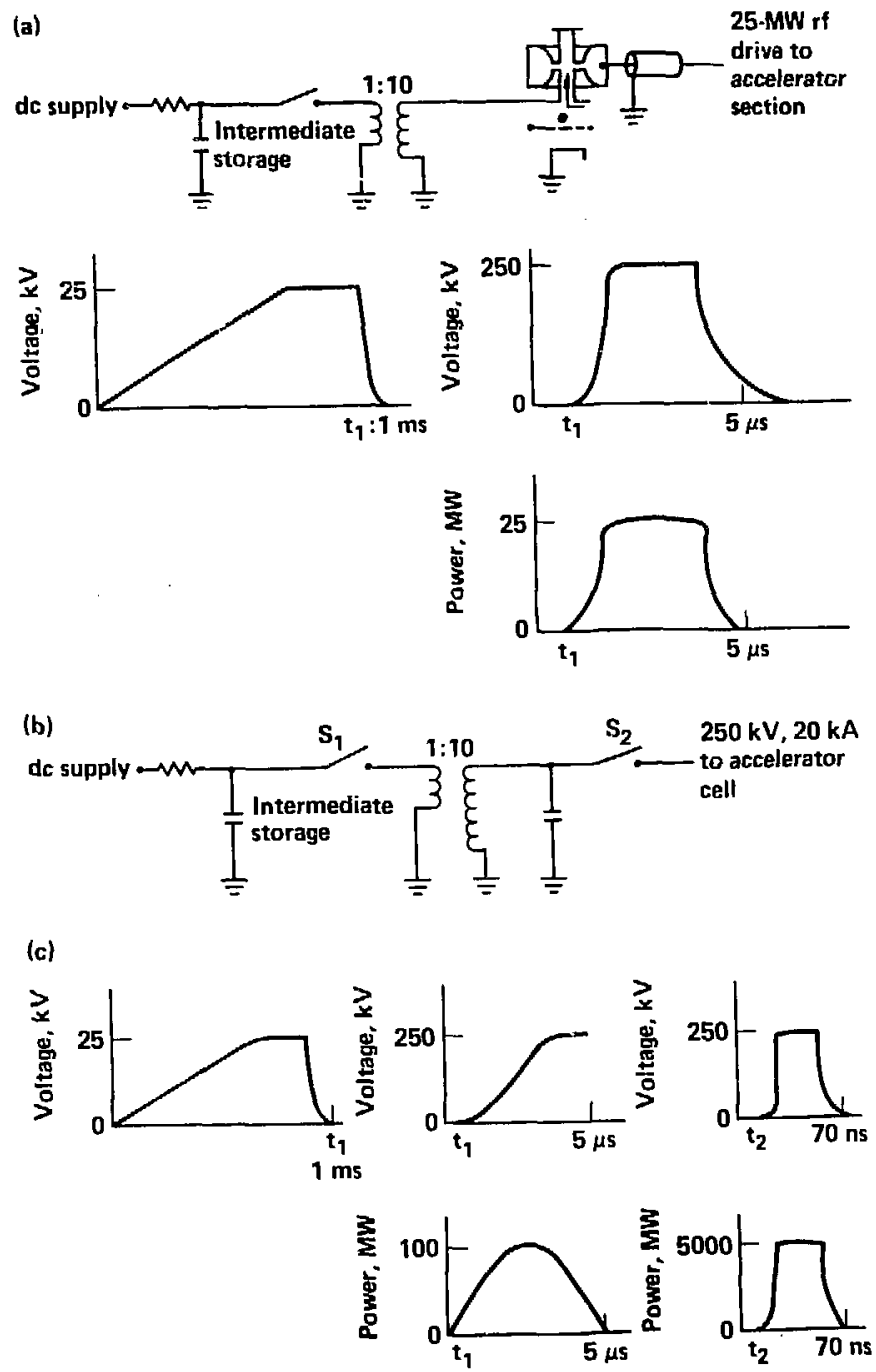

Figure 1 


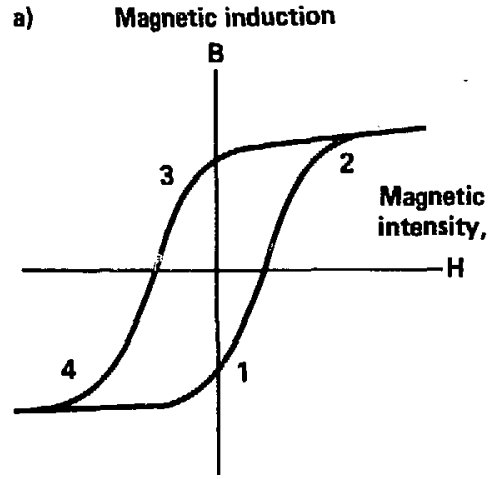

b)

Saturable inductor
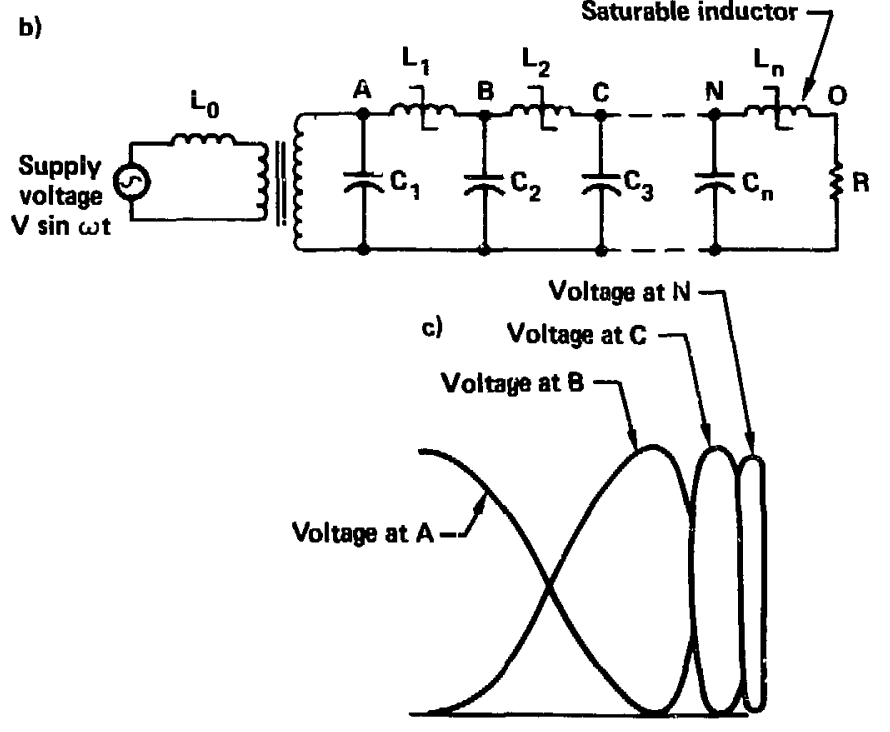

Figure 2 

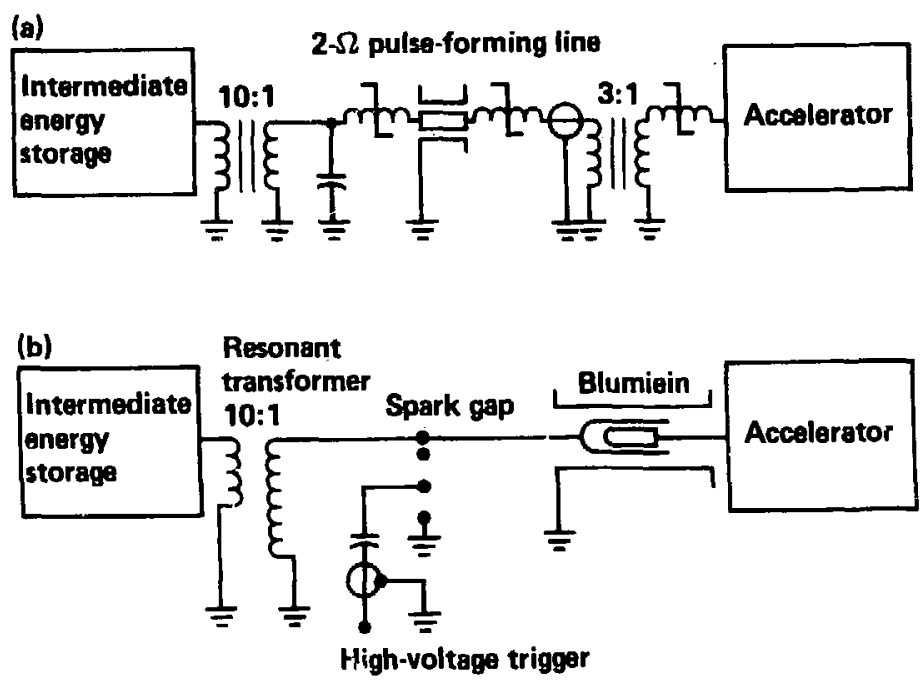

Figure 3 
(a)

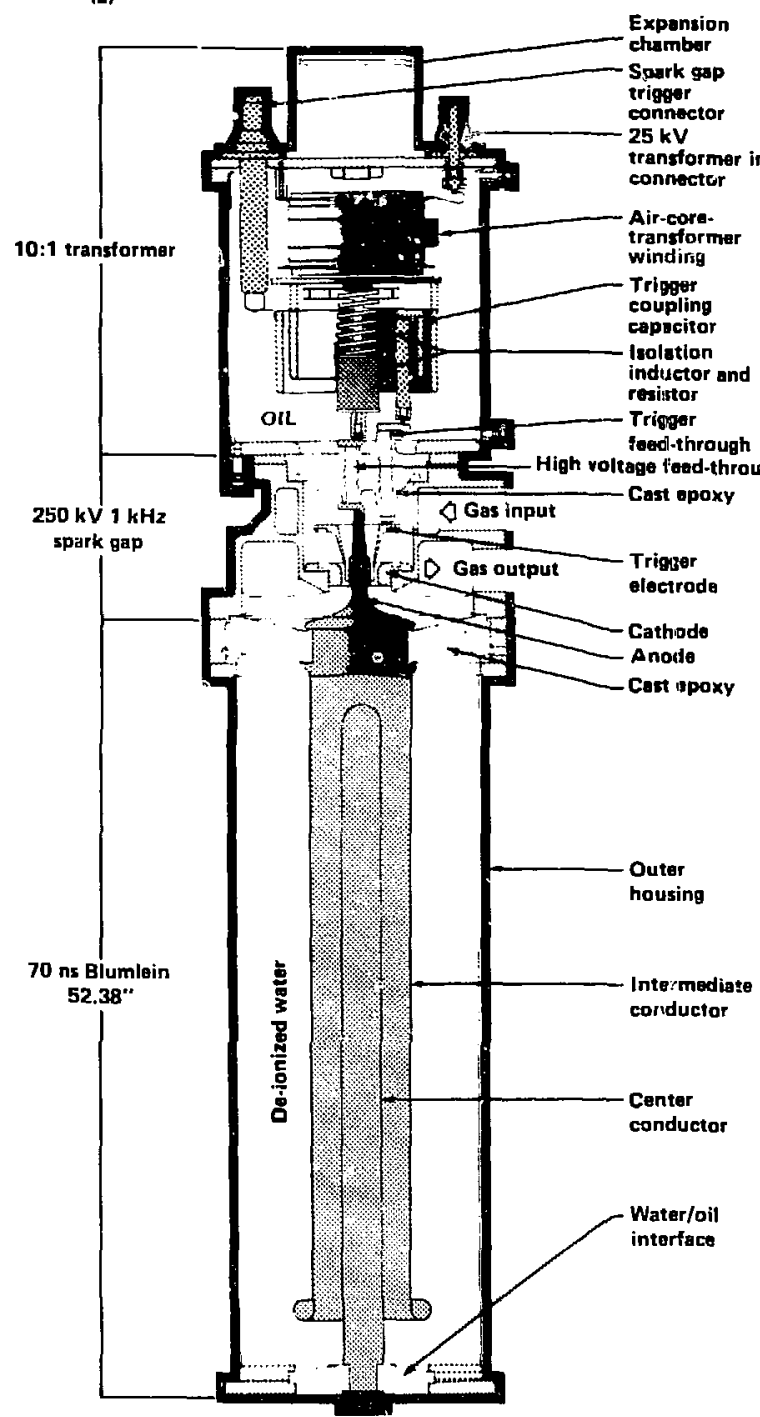

(b)

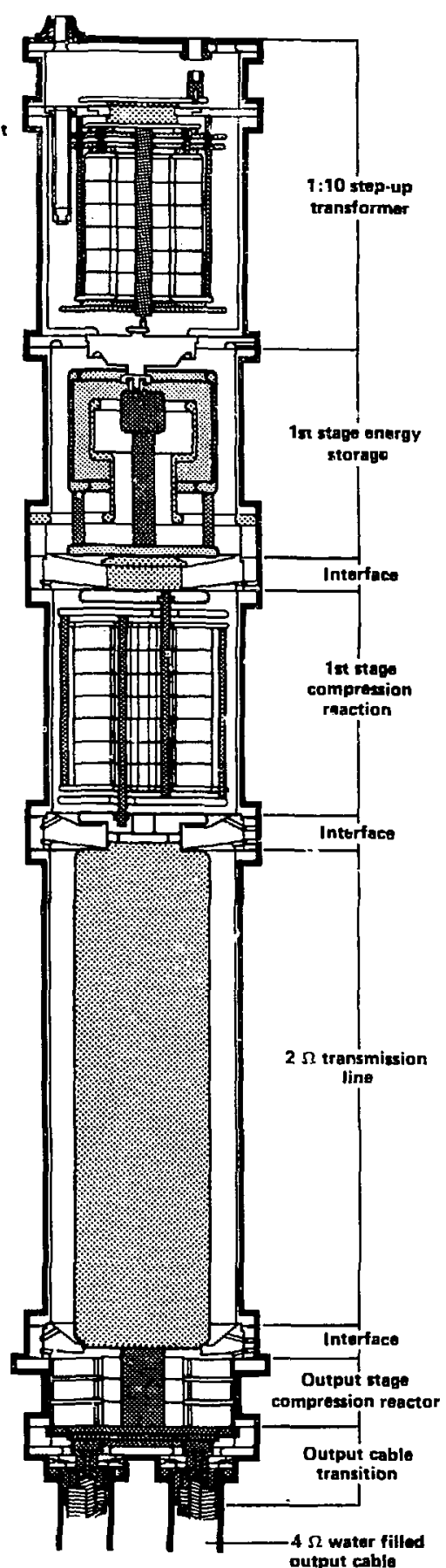

Figure 4 

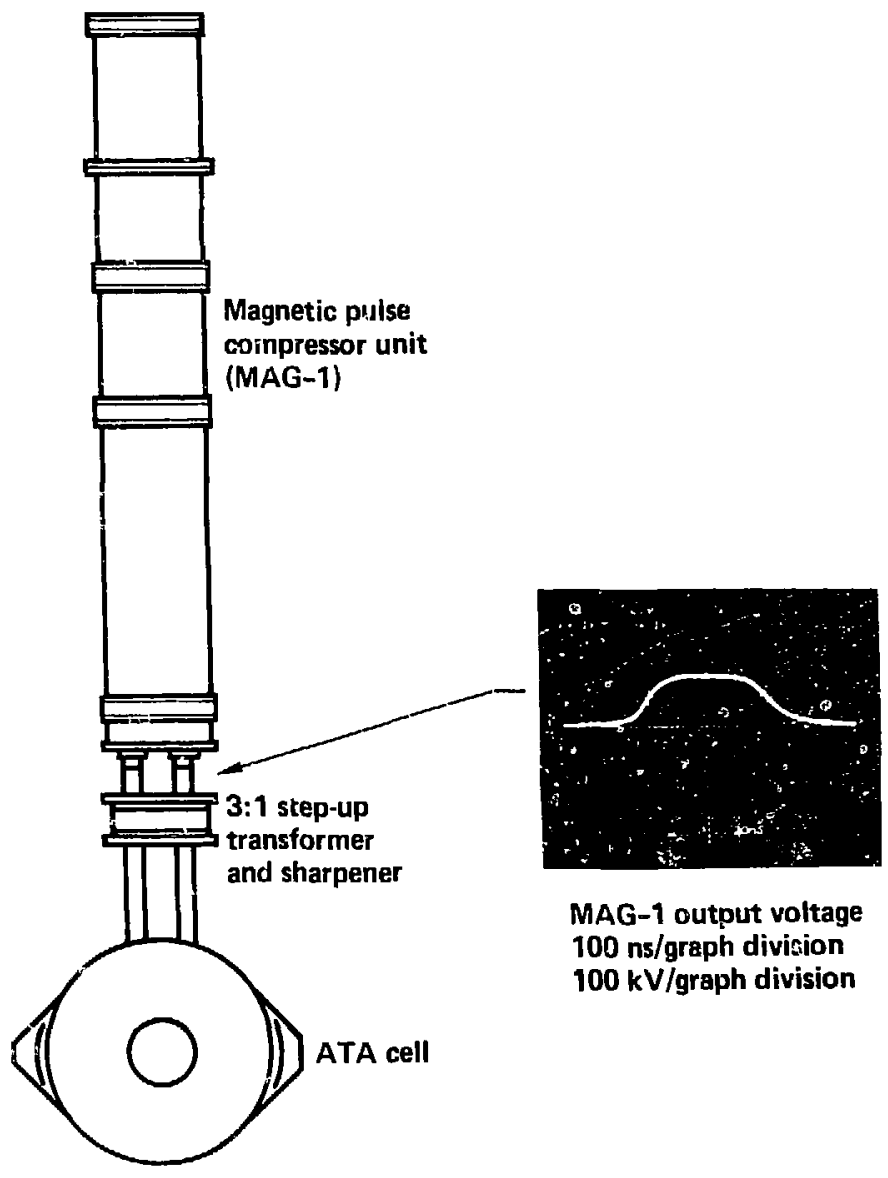

MAG-1 output voltage $100 \mathrm{~ns} / \mathrm{greph}$ division $100 \mathrm{kV} / \mathrm{graph}$ division

Figure 5 


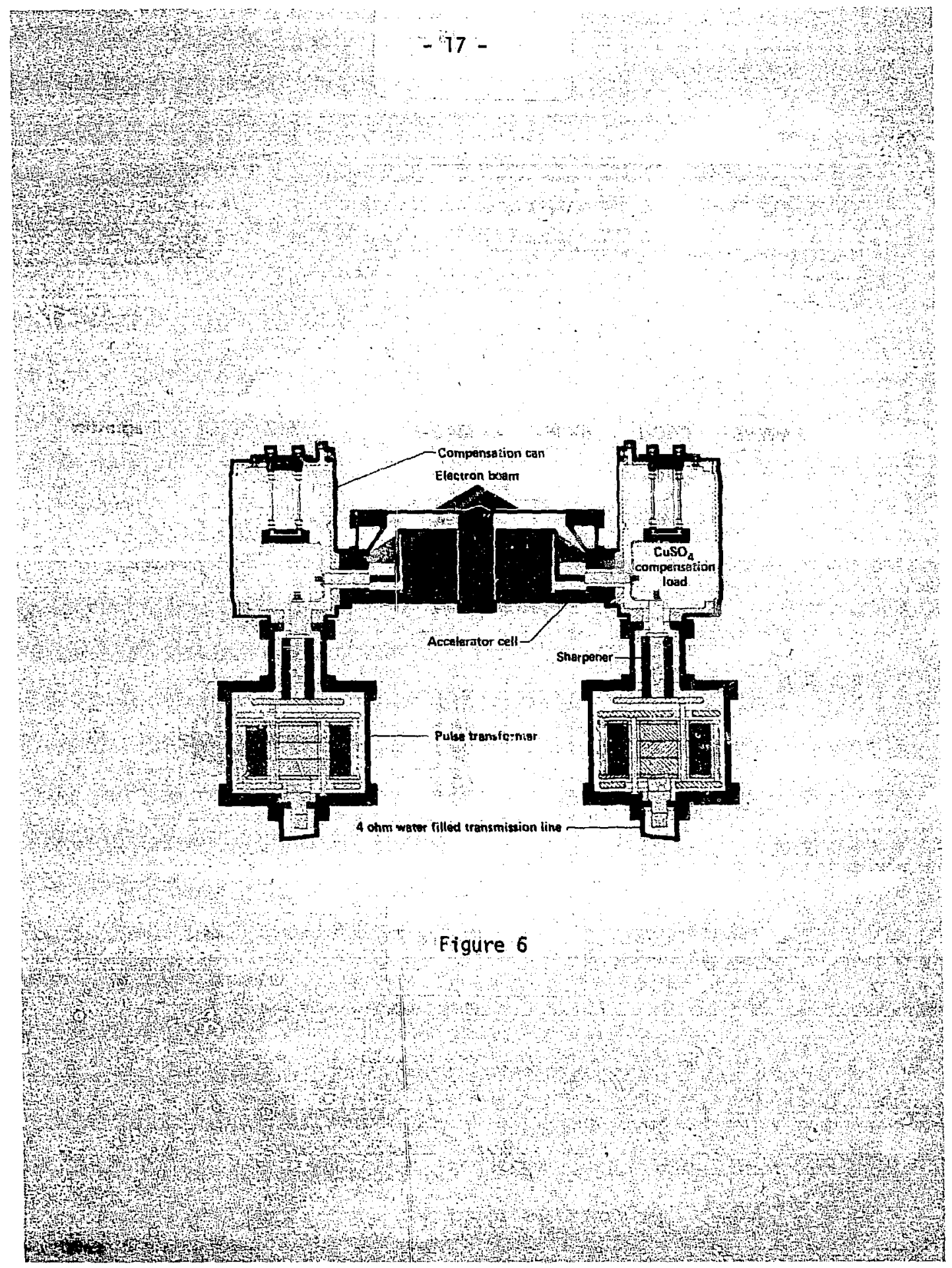




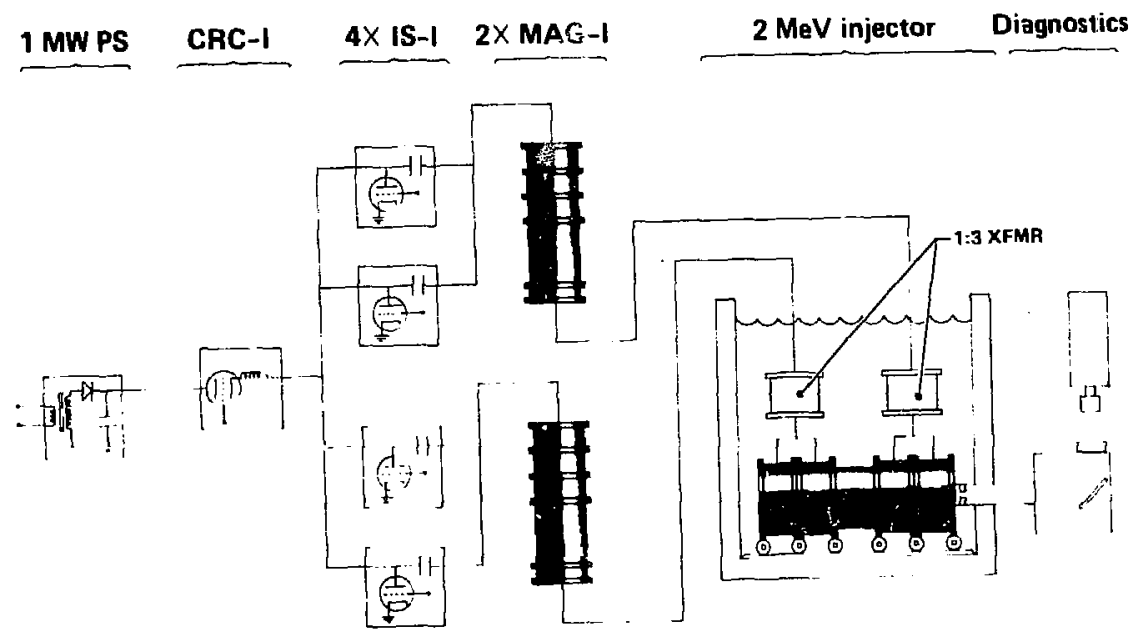

Figure 7 


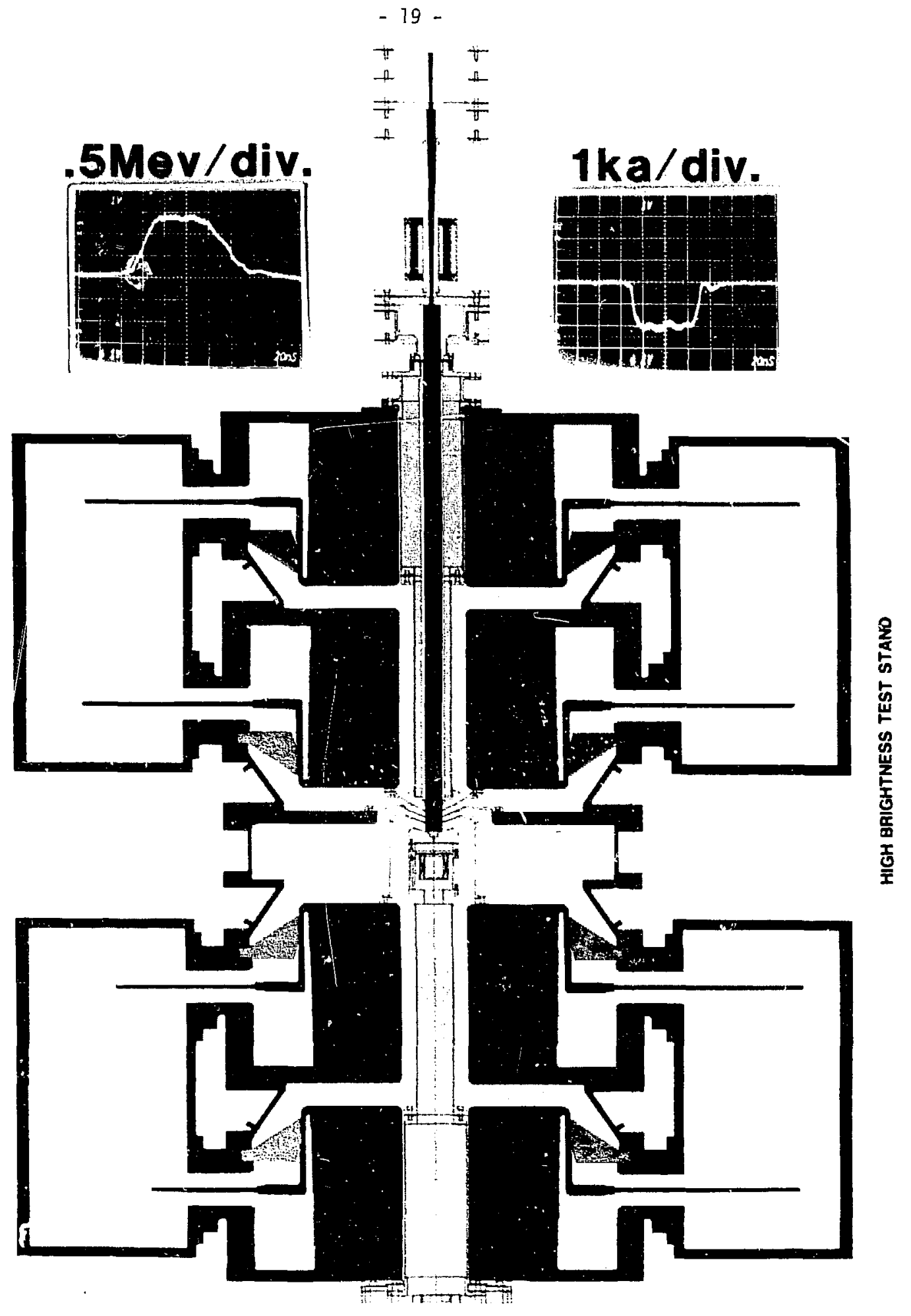

Figure 8 